\title{
COMMENTARY
}

\section{Local public services and sustainable development goals: From a national perspective to a European joint action}

\author{
Mariano Votta ${ }^{1^{*}}$ Tiziana Toto $^{1}$ Cinzia Pollio $^{1}$ Michaela Papavero $^{1}$ \\ ${ }^{1}$ Cittadinazattiva APS, Via Cereate 6, 00183 Rome, Italy
}

\section{Check for updates}

Correspondence to: Mariano Votta, Active Citizenship Network, c/o Cittadinazattiva APS, Via Cereate 6, 00183 Rome, Italy;

E-mail: m.votta@ cittadinanzattiva.it

Received: March 17, 2021;

Accepted: April 19, 2021;

Published: April 23, 2021

Citation: Votta M, Toto T, Pollio C, et al. Local public services and sustainable development goals: From a national perspective to a European joint action Resour Environ Econ, 2021, 3(1): 245-250.

https://doi.org/10.25082/REE.2021.01.004

Copyright: (c) 2021 Mariano Votta, et al. This is an open access article distributed under the terms of the Creative Commons Attribution License, which permits unrestricted use, distribution, and reproduction in any medium, provided the original author and source are credited.

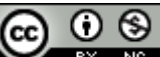

\begin{abstract}
Local public services are a benchmark in the development of a sustainable society and attainment of the goals set by Agenda 2030. Therefore, it is necessary to gather information and hear directly from the citizens, who constantly deal with this realm, how their country performs in the provision of qualitative and sustainable services. In Italy, for instance, there is a low level of consideration and contentment in terms of the quality, management, and efficiency of public services. In particular, the local public transport sector stands out as the lowest rated by citizens. This manuscript has two main functions. First, it provides the results of a civic consultation conducted during 2020 in Italy by the Italian consumer organization Cittadinanzattiva APS, which informs about the perceptions and outlooks of citizens towards the reality of local public services that are a constant in their daily life. Second, it introduces a new political initiative promoted at European level in the field of sustainability and consumer protection: The InterInstitutional Group "Sustainable Development Goals for well-being and consumers' protection", officially launched last February 16th, 2021. An initiative that represents the desire of the civil society to contribute to the SDGs, the "New Consumer Agenda" [1], and the "Green New Deal" [2] and that aims at discussing and raising awareness on how each one of us as EU citizen can give their contribution, convinced that citizen and consumer's empowerment should be the pillar of the transition towards a more inclusive and sustainable Europe.
\end{abstract}

Keywords: public services, sustainability, public transport, water service, waste management, civic survey, common goods, civic participation, consumers' rights, Italy, European Union

\section{Introduction}

What is Italy's situation concerning the achievement of the sustainable development goals? We asked it to the citizens since they are protagonists in promoting and facilitating change by adopting a conscious and responsible behavior. We assumed that local public services constitute the essential basis for the sustainable development of our cities because they are a crucial tool of social solidarity, wealth redistribution, and the exercise of citizenship rights. In light of this consideration, specific goals $(3,6,11$ e 12) and reference targets were selected, for which we detected a "feasibility judgment" expressed by citizens regarding the achievement of the following 2030 Agenda goals [3]:

(1) Target 3.6 of goal 3: by 2020, halve the number of global deaths and injuries from road traffic accidents;

(2) Target 6.3 of goal 6 : by 2030 , improve water quality by reducing pollution, minimizing release of hazardous chemicals and materials, halving the proportion of untreated wastewater and substantially increasing recycling and safe reuse globally;

(3) Target 6.4 of goal 6: by 2030, substantially increase water-use efficiency across all sectors and ensure sustainable withdrawals and supply of freshwater to address water scarcity and substantially reduce the number of people suffering from water scarcity;

(4) Target 11.2 of goal 11: by 2030, provide access to safe, affordable, accessible and sustainable transport systems for all, improve road safety, in particular by expanding public transportation systems, including by special attention to vulnerable people's need, such as women, children, people with disabilities and older people;
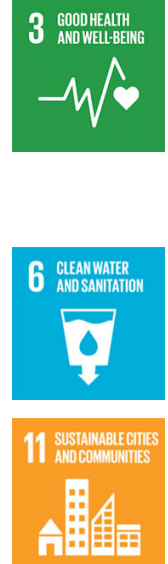
(5) Target 11.6 of goal 11: by 2030, reduce the adverse per capita environmental impact of cities, including by special attention to air quality and municipal and other waste management;

(6) Target 12.5 of goal 12 : by 2030 , substantially reduce waste generation

rough prevention, reduction, recycling and reuse.

\section{Materials and methods}

Cittadinanzattiva is an Italian NGO officially recognized as a consumer organization at the national level and appointed to represent the Italian consumer organization in front of the EU Commission in the context of "The European Consumer Consultative Group (2016-2019 mandate)" [4]. During 2020 Cittadinanzattiva carried out a civic consultation based on a statistically no representative sample of citizens-users; moreover, the evaluation for each target examined has been integrated and compared with additional data, available to the organization, with the purpose of explicating or confute the citizens' assessment over the Agenda 2030's goals realization.

Data used in the survey have a double nature, a subjective and objective one. The subjective one considers citizens' opinions on quality, costs, accessibility, and protection related to the local public services (LPS), in their cities.

To this purpose, we reached 3,586 citizens (almost 90\% aged 18-65) who participated in the consultation, of which $45 \%$ has a high school diploma and about $44 \%$ has a bachelor's degree. Moreover, $40 \%$ of the respondents come from the center of Italy, 37\% from the North, and $23 \%$ from the South. The objective analysis involved data coming from dossiers of the "Observatory prices

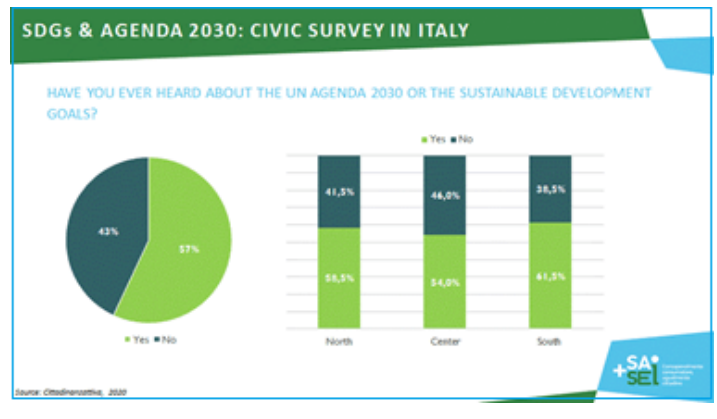
and tariffs" (The Observatory prices and tariffs of Cittadinanzattiva was founded in 2005 with the aim to compare the different pricing policies applied to public utilities and adopted in the various geographical areas of Italy; assess its impact on daily activities of the users; inform citizens about the mechanisms of detection rates, on the phenomena related to the performance of the same and the reference standard.) [5], an entity of Cittadinanzattiva that conducts yearly studies on transports, waste and water in 110 regional county seats. The main outputs of the survey have been presented in the context of the "Festival for the sustainable development" in October 2020 [6], promoted by the Italian Alliance for Sustainable Development (ASviS).

\section{Ethics statement}

Every author listed in this article has contributed to the collection of data, analysis and research design of the work reported. The authors and co-authors of this article share responsibility and accountability for the provided content. This article is not the product of plagiarism, but it is an original work of the cited authors. Data reported in this article are subjected to maximum transparency and accuracy, as they were displayed during and after the survey.

\section{Results}

Citizens are not completely satisfied with the public services in their cities; in fact, there is a gradually decreasing level of satisfaction from the North to the South of the country. Water service is the most appreciated, followed by the waste collection one, while the local public transport ranked last. But how is Italy doing with regard to the achievement of sustainable development goals? According to citizens, it is not doing so well: almost half of them have little faith in the possibility of improving and making these sectors sustainable, as indicated by the Agenda 2030's goals.

The consultation focused mainly on three sectors: local public transport, water service, and urban waste management. In particular, more than two users out of three think their city cannot guarantee accessible, safe, and sustainable public transport by 2030, as established by the Agenda, and that it will not be possible to halve the number of deaths or injuries for 
road accident at the global level. Nearly more than one citizen out of two thinks it will not be feasible to improve water quality and safety by 2030 , and less than half say that the number of people suffering from water shortage will not be reduced substantially, as expected by Agenda 2030's goal 6. Almost 53\% believes that there will be a reduction in waste production, but the percentage falls to $48 \%$ among those who deem the goal of cutting the consequent environmental impact possible.

To sum up, the general panorama seems quite negative with results that highlight a notably low level of users' satisfaction in the local public transport sector and a spread distrust over the attainment of sustainability goals. Let's now examine more deeply each sector.

\subsection{Perception on public transport}

In sight of average spending of about $€ 300$ for the annual pass [7], citizens complain about the poor accessibility to the local public transport in terms of architectural barriers, service extensiveness, and the availability of the client service (consultation's average score of 2.07 in a scale 1-4); plus, they declare to be "a little satisfied" of the quality (score 2.31) in terms of cleaning,

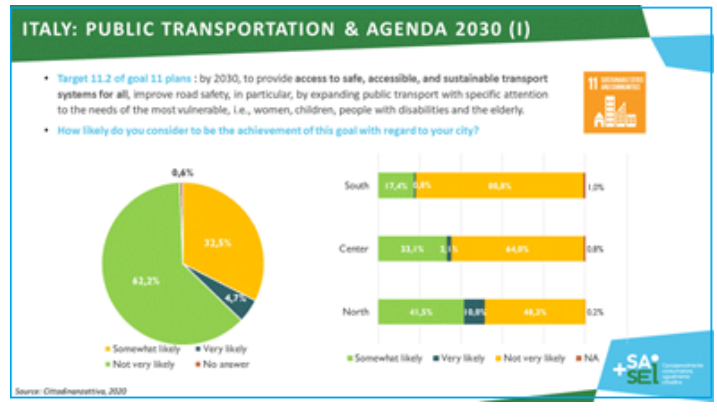
punctuality, and continuity, and "not at all satisfied" (the total average score is 1.83) in the protection category, evaluated in terms of availability of info regarding how to submit a claim, complaint management, reimbursements, and conciliation process. In fact, the indicators of quality and forms of protection are scarcely treated in the Service Charters of transport companies. Therefore, even though the public transportation cost is far lower compared to that of other European countries, citizens are worse off on the front of quality and efficiency of the services that hinder a consequent good accessibility.

\subsection{Perception on water service}

In sight of an average family spending of $€ 434$ in 2019 [8], most citizens believe to be "somewhat satisfied" with the service's continuity and regularity in their city (the average score is 3.19 on a scale of 1-4). Here again, the satisfaction level decreases compared to the complaint, conciliation, and expected reimbursements management (indicated value is slightly more than score 2). In de-

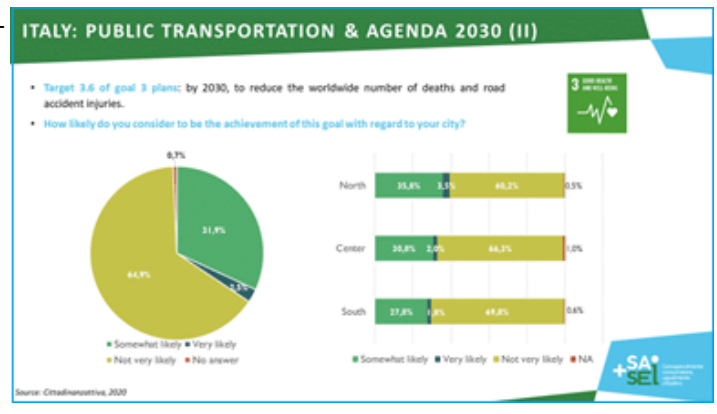
tail, $38 \%$ of the respondents are "a little satisfied" with the complaint management and $35 \%$ "of the available info to submit a claim"; $48 \%$ denounces the absences of indemnities where disservices should take place, and $59 \%$ denounces the absences of conciliation proceedings.

\subsection{Perception waste management service}

In sight of an average family spending of $€ 300$ in 2019 [9], most citizens claim they are "a little satisfied" with the service's value for money (average score 2.36), 59\% says they are "a little or at all satisfied" with the quality, in particular with the bin maintenance and cleaning, whose frequency of cleaning information is absent in $54 \%$ of the examined Service Charters. Little

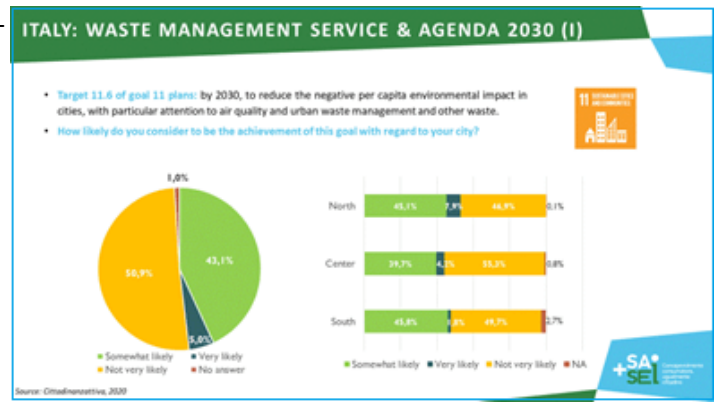


more than 50\% say they are "at all or a little satisfied" with the street cleaning and sweeping service, whose information is absent in $63 \%$ of the analyzed Charters.

The field of protection seems to be the weakest even in this service: in fact, most citizens say they are "a little satisfied" with the tools it has (average score 2.24). This judgment finds confirmation in our Charters analysis: even in this case, indeed, the Charters result to be lacking very important information.

\subsection{Trustless citizens because unsatisfied with the services}

Citizens' little trust in the possibility of achieving the Agenda 2030 goals derives from an evident dissatisfaction with the quality of services provided at local level. Therefore, Cittadinanzattiva believes that it is necessary to intervene on certain aspects for the services' good functioning: for example, by enlarging the network and means provided to the public transport, by im-

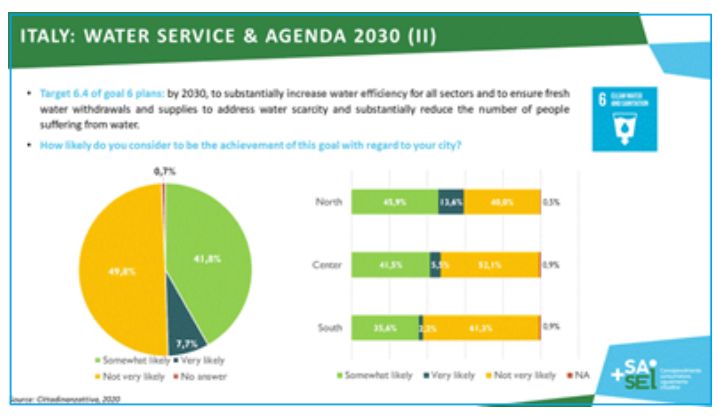
proving the complaint management and dispute resolution in every field, by interceding in the waste management service, in particular for what regards costs- considered excessive by citizens- and legal protections, which are still too marginal or even inexistent at all.

To demonstrate this, the survey highlights that only $4,7 \%$ of the citizens consider 'very likely the achievement of sustainability in the field of transport system, compared to $62,2 \%$ that considers it 'not very likely. Opinions over goal 6 , concerning water quality and pollution reduction, are not really different: $51,5 \%$ deems it as 'not very likely' compared to $6,9 \%$ that sees it as 'very likely'.

\section{Discussion and conclusion}

These results and the ongoing obstacles to the improvement of public services and wellbeing presented by the Covid-19 pandemic highlight, now more than ever, the importance of cooperation between all actors involved: institutions, companies that provide public services, associations that represent the point of view of users, media, researchers, experts, regulatory bodies, etc. In particular, this cooperation should also be sought at European level and in each Member State to ensure and protect citizens' welfare in all the above-mentioned aspects.

From our perspective, we hope that this analysis will be repeated over the years in order to record, from a civic point of view, both the advances and the challenges towards the achievement of the SDGs by the public utility services in Italy. At the same time, we hope that a similar analysis can be carried out for a range of different public services and that the data that emerges can be useful for policymakers called to manage the Recovery Plan in the country. Furthermore, it would be useful to compare the situation of public services in the various EU countries with a similar methodology.

In this regard, also taking into account the dissatisfying status of public services and willingness to foster citizens' participation in the development of the "New Consumer Agenda" (The New Consumer Agenda, adopted on 13 November 2020 by the European Commission, gives back momentum to the EU consumer policy, aiming to better equip the EU to tackle the new challenges to consumer rights and opportunities for consumer empowerment brought about by the green and digital transitions, the COVID pandemic and the plans for post-COVID recovery. ) [10] and the "Green New Deal" [11], and given the multiple challenges posed to the achievement of sustainability, Cittadinanzattiva, through its EU branch called "Active Citizenship Network", together with the umbrella organization "European Consumers Union Association" (ECU) [12] and the think tank "Italian Alliance for Sustainable Development" (ASviS) [13], launched last 16 of February 2021 the Inter-institutional Group "SDG's for well-being and consumers' protection." The latter is a political initiative at the EU level to assist and strengthen the practices depending on the Sustainable Development Goals across Europe as well as to strengthen and boost programs for the enhancement and sustainability of all the public services available to citizens [14].

Endorsed by 50 European and National Associations (coming from 24 countries), it has already received the support of eight members of the European Parliament and seeks to broaden contacts within the European Union for the enrichment and contribution to the policy-making 
process in the field of sustainable development. The Group is open to all types of actors, private and public, that are willing and able to contribute to consumer policies and the goals set by the Agenda 2030.

We strongly believe that the active participation of European citizens should be at the base Inter-Institutional Group of this transition, and with this SDGs for well-being and consumers' protection aim the promoting associations of the Inter-Institutional Group want to strengthen the dialogue with the European institutions, convinced that - now more than ever - there is the need of a European Union closer to its citizens. This need is made even more urgent by the rising of new challenges that are creating first-class and second-class citizens in the accessibility to primary goods and public services, starting from healthcare services but not only. We are convinced that these issues should be at the centre of the Conference on the Future of Europe. And from our perspective, the Inter-institutional Group "SDG's for well-being and consumers' protection" is ideally a concrete example, a translation into practice, of the thematic "citizens' agoras" encouraged by by the Resolution voted last January 2020 on the European Parliament's position on the Conference on the Future of Europe [15].

\section{Conflict of interest and funding}

The above results were reported by Cittadinanzattiva through its civic consultation on local public services and sustainable development goals as part of the project "Consapevolmente consumatore, ugualmente cittadino" ("Consciously consumer, equally citizen") [16] financed by the Italian Minister of economic development according to the DM of February 7th, 2018. The political initiative of the Inter-institutional Group "SDG's for well-being and consumers' protection" has been self-financed by the three promoter associations.

\section{Acknowledgements}

We thank the decennial activity of the "Observatory prices and tariffs" of Cittadinanzattiva for providing this study with data and findings taken from its investigations on pricing policies and public utilities. The author also thanks the "European Consumers Union" and the "Italian Alliance for Sustainable Development" for their dedication and cooperation within the InterInstitutional Group.

\section{References}

[1] New Consumer Agenda: European Commission to empower consumers to become the driver of transition, 13 Nov. 2020, European Commission, viewed April 12, 2021. https://ec.europa.eu/commission/presscorner/detail/en/ip_20_069

[2] A European Green Deal, n.d., European Commission, viewed April 12, 2021 https://ec.europa.eu/info/strategy/priorities-2019-2024/european-green-deal_en

[3] The 17 goals, n.d., UN Department of Economic and Social Affairs, viewed April 10, 2021. https://sdgs.un.org/goals

[4] Register of Commission Expert Groups and Other Similar Entities, 2020, European Commission, viewed April 12, 2021. https://ec.europa.eu/transparency/regexpert/?do=groupDetail.groupDetail\&groupID=849\&Lang=e n\&LangSelect $=1$

[5] Observatory prices and tariffs, 2021, Cittadinanzattiva, viewed April 11, 2021. https://www.cittadinanzattiva.it/corporate/consumatori/7070-observatory-prices-and-tariffs.html

[6] Festival dello sviluppo sostenibile 2020, 2020, viewed April 12, 2021. https://festivalsvilupposostenibile.it/2020

[7] Trasporto pubblico locale: i dati 2020 dell'Osservatorio di Cittadinanzattiva, 18 Sept. 2020, Cittadinanzattiva, viewed April 11, 2021. https://www.cittadinanzattiva.it/primo-piano/consumatori/13542-trasporto-pubblico-locale-i-dati2020-dell-osservatorio-di-cittadinanzattiva.html

[8] I dati dellOsservatorio Prezzi e Tariffe sul servizio idrico integrato, 18 Giugno 2020, Cittadinanzattiva, viewed April 12, 2021.

https://www.cittadinanzattiva.it/primo-piano/consumatori/13361-i-dati-dell-osservatorio-prezzi-e -tariffe-sul-servizio-idrico-integrato.html 
[9] Rifiuti: 300 euro a famiglia nel 2020. I nuovi dati dell'Osservatorio Prezzi e Tariffe di Cittadinanzattiva, 25 Nov. 2020, Cittadinanzattiva, viewed April 10, 2021.

https://www.cittadinanzattiva.it/primo-piano/consumatori/13735-rifiuti-300-euro-a-famiglia-nel-2 020-i-nuovi-dati-dell-osservatorio-prezzi-e-tariffe-di-cittadinanzattiva.html

[10] New Consumer Agenda: European Commission to empower consumers to become the driver of transition, 13 Nov. 2020, European Commission, viewed April 12, 2021. https://ec.europa.eu/commission/presscorner/detail/en/ip_20_069

[11] A European Green Deal, n.d,., European Commission, viewed April 12, 2021. https://ec.europa.eu/info/strategy/priorities-2019-2024/european-green-deal_en

[12] European Consumers union, n.d., viewed April 12, 2021. https://europeanconsumersunion.eu/about-us/?lang=en

[13] Alleanza Italiana per lo sviluppo sostenibile, n.d., viewed April 13, 2021. https://asvis.it/who-we-are/

[14] Inter-Institutional Group “SDGs for well-being and consumers' protection”, 2021, viewed April 13, 2021. http://www.interestgroupsdgs.eu/

[15] European Parliament resolution of 15 January 2020 on the European Parliament's position on the Conference on the Future of Europe, 15 Jan. 2020, European Parliament, viewed April 10, 2021. https://www.europarl.europa.eu/doceo/document/TA-9-2020-0010_EN.html

[16] Consapevolmente consumatore, ugualmente Cittadino, 2021, viewed April 10, 2021. https://www.piusaipiusei.org/ 